\title{
Violência contra a mulher: uma análise das notificações no estado da Paraíba
}

\begin{abstract}
RESUMO | Objetivo: Tem-se por objetivo: analisar à luz da epidemiologia, as notificações violência contra a mulher no estado da Paraíba. Método: Esta pesquisa é uma revisão integrativa da literatura, descritiva, qualitativa e exploratória. A coleta de dados ocorreu em julho, ano de 2021, buscando dados mais recentes sobre as publicações que abordavam a respeito das notificações de violência contra a mulher. Foram usadas as seguintes bibliotecas eletrônicas na área da saúde: SciELO-Scientific Electronic Library Online e Google acadêmico. Os dados foram organizados em um quadro. Resultados: Com 7 publicações, percebeu-se, que a violência vem se mantendo constante ao longo do tempo quanto ao seu número de notificações, evidenciando assim o aumento do número de denúncias por parte das mulheres vítimas de agressões físicas. Conclusão: A violência contra a mulher é um problema de saúde pública, social e educacional, e por vezes, é negligenciada pela sociedade, por medo e opressão.
\end{abstract}

Descritores: Violência; Mulher; Saúde; Cuidado.

ABSTRACT | Objective: The objective is: to analyze, in the light of epidemiology, the notifications of violence against women in the state of Paraíba. Method: This research is an integrative, descriptive, qualitative and exploratory literature review. Data collection took place in July, year 2021, seeking more recent data on publications that addressed the notifications of violence against women. The following electronic libraries were used in the health area: SciELO-Scientific Electronic Library Online and Academic Google. Data were organized in a frame. Results: With 7 publications, it was noticed that violence has been constant over time as to its number of notifications, thus showing the increase in the number of complaints by women victims of physical aggression. Conclusion: Violence against women is a public health, social and educational problem, and is sometimes neglected by society, due to fear and oppression.

Descriptors: Violence; Women; Health; Caution

RESUMEN | Objetivo: El objetivo es: analizar, a la luz de la epidemiología, las notificaciones de violencia contra la mujer en el estado de Paraíba. Método: Esta investigación es una revisión de literatura integradora, descriptiva, cualitativa y exploratoria. La recolección de datos se llevó a cabo en julio del año 2021, buscando datos más recientes sobre publicaciones que abordan las notificaciones de violencia contra las mujeres. Se utilizaron las siguientes bibliotecas electrónicas en el área de la salud: SciELOScientific Electronic Library Online y Academic Google. Los datos se organizaron en un marco. Resultados: Con 7 publicaciones, se notó que la violencia ha sido constante en el tiempo en cuanto a su número de notificaciones, evidenciando así el incremento en el número de denuncias de mujeres víctimas de agresión física. Conclusión: La violencia contra la mujer es un problema de salud pública, social y educativa, y en ocasiones es descuidado por la sociedad debido al miedo y la opresión.

Descriptores: Violencia; Mujeres; Salud; Precaución.

\section{Ana Flávia Freitas de Miranda Coêlho}

Enfermeira. Centro Universitário de João Pessoa.

ORCID: 0000-0003-2583-9235.

\section{Rosicleide Rúbia Pereira Medeiros}

Enfermeira. Pós-graduada em obstetrícia e neonatologia. Mestranda no programa de pós-graduação em educação, trabalho e inovação em medicina na Universidade Federal do Rio Grande do Norte. ORCID: 0000-0002-3442-7999

\section{Luciene de Souza Santos Albuquerque}

Enfermeira. Centro Universitário de João Pessoa.

ORCID: 0000-0001-5119-195X

\section{Izabelita Félix de Oliveira \\ Enfermeira. UNIFIP. \\ ORCID: 0000-0001-5883 \\ Maria Clara Ribeiro Costa \\ A}

Enfermeira. Centro Universitário de João Pessoa.

ORCID: 0000-0003-4422-3719

\section{Lúcia Gomes de Souza Silva}

Enfermeira. Faculdade Maurício de Nassau. Pós-graduada em Urgência/Emergência e Unidade de Terapia Intensiva. ORCID: 0000-0001-6998-435X

Recebido em: 27/08/2021

Aprovado em: 30/11/2021

INTRODUÇÃO violência contra a mulher é qualquer ato ou conduta que seja baseada no gênero e que venha a causar morte, dano ou sofrimento físico, sexual ou psicológico à saúde da mulher, sendo ela em âmbito público ou privado. Ela pode atingir mulheres de diferentes orientações sexuais, classe sociais, origens, estados civis, escolaridade, raças/ etnias em relações desiguais de poder, podendo acontecer desde a infância até a velhice e em todos os âmbitos sociais (1).

No Brasil podem-se observar avanços no campo legal e social, bem como na criação de organismos em defesa das mulheres vítimas de violência, dentre eles: as Delegacias de defesa das mulheres, Centro de Atendimentos 
especializados, casas abrigos, centrais de atendimentos telefônicos de emergência, entre outros mecanismos de apoio(2).

Contudo, a violência contra mulher é um problema com uma visibilidade política e social recente devido ao momento de gravidade das situações de violências sofridas pelas mulheres. A questão da violência contra a mulher só começou a ser colocada em destaque pelos movimentos feministas no Brasil, no ano de 1980, em um evento, que foi o II Congresso da Mulher Paulista(3).

Apenas em 2016, criou-se a Lei $n^{\circ}$ 11.340 conhecida como "Lei Maria da Penha", sancionada no dia 7 de agosto de 2006, pelo então Presidente da República, Luiz Inácio Lula da Silva, que se tornou um dispositivo legal na busca de minimizar os atos de violência sofridos pela mulher, no qual vem especificando no seu artigo $7^{\circ}$ as violências sofridas pelas mulheres, como sendo físicas, psicológicas, sexuais, patrimoniais ou morais(4). A notificação dos casos de violência é um instrumento obrigatório, que possibilita as autoridades legais, ter o conhecimento da situação de vulnerabilidade que a mulher se encontra, no qual os profissionais da saúde, educação, assistência social e outros, devem estar atentos(5).

Sendo assim, levantou-se a seguinte questão de pesquisa: Como se dá as notificações de violência contra a muIher no estado da Paraíba? Tem-se por objetivo: analisar à luz da epidemiologia, as notificações violência contra a mulher no estado da Paraíba.

\section{MÉTODO}

Esta pesquisa é uma revisão integrativa da literatura, descritiva, qualitativa e exploratória. A coleta de dados ocorreu em julho, ano de 2021, buscando dados mais recentes sobre as publicações que abordavam a respeito das notificações de violência contra a mulher.
Foram usadas as seguintes bibliotecas eletrônicas na área da saúde: SciELO-Scientific Electronic Library Online e Google acadêmico. Para a seleção da pesquisa, foi preciso estabelecer alguns critérios de inclusão, que foram: publi-

Apenas em 2016, criou-se a Lei $n^{\circ}$ 11.340 conhecida como "Lei Maria da Penha", sancionada no dia 7 de agosto de 2006, pelo então Presidente da República, Luiz Inácio Lula da Silva, que se tornou um dispositivo legal na busca de minimizar os atos de violência sofridos pela mulher [...]

cações em inglês, português e espanhol, gratuitas e integrais, publicadas entre os anos de 2016 e 2021. Foram excluídas as publicações que se apresentavam fora desses critérios.

$\mathrm{Na}$ busca pelas publicações, foi usado o operado booleano AND, com os descritores: Violência; Mulher; Saúde e Cuidado. Com o auxílio do programa da Microsoft Word, os estudos foram organizados em um quadro para apreciação. Não houve a necessidade de submeter a pesquisa ao Comitê de ética em pesquisa, por ser um estudo na literatura. Para selecionar as publicações, foi usado um instrumento, na modalidade fichamento, criado pelas autoras deste estudo.

No total, foram encontradas 115 publicações que tinham probabilidade de ter alguma relação com o tema estudado. Filtrando o período de tempo, seguiram 45 publicações em análise. Após isso, foi realizada a leitura dos títulos das publicações, no qual somente 26 respondiam ao objetivo do estudo e citavam os descritores do tema. Em seguida, foi feita a análise do resumo destas 26 publicações, e a partir disso, foram selecionadas para leitura integral 7 publicações, pois, estas se encontravam contempladas dentro de todos os critérios de inclusão da pesquisa. A validação por dois pesquisadores conhecedores da temática foi realizada.

\section{RESULTADOS}

O quadro abaixo analisou as publicações que abordavam sobre as notificações, expondo os: autores, títulos, ano de publicação, periódico e achados científicos sobre as notificações de violência contra a mulher.

Foram encontradas publicações que abordavam desde a ausência de domínio, capacitação e conhecimento sobre a notificação, até aquelas que traziam uma assistência deficitária ofertada a mulher que sofreu violência. Predominaram-se publicações do ano de 2016. O enfermeiro foi visto como uma figura importante nesse processo, mas que necessita de capacitação para realizar melhores condutas.

DISCUSSÃO 


\section{QUADRO 1- Apresentação das publicações sobre notificações de violência contra a mulher:}

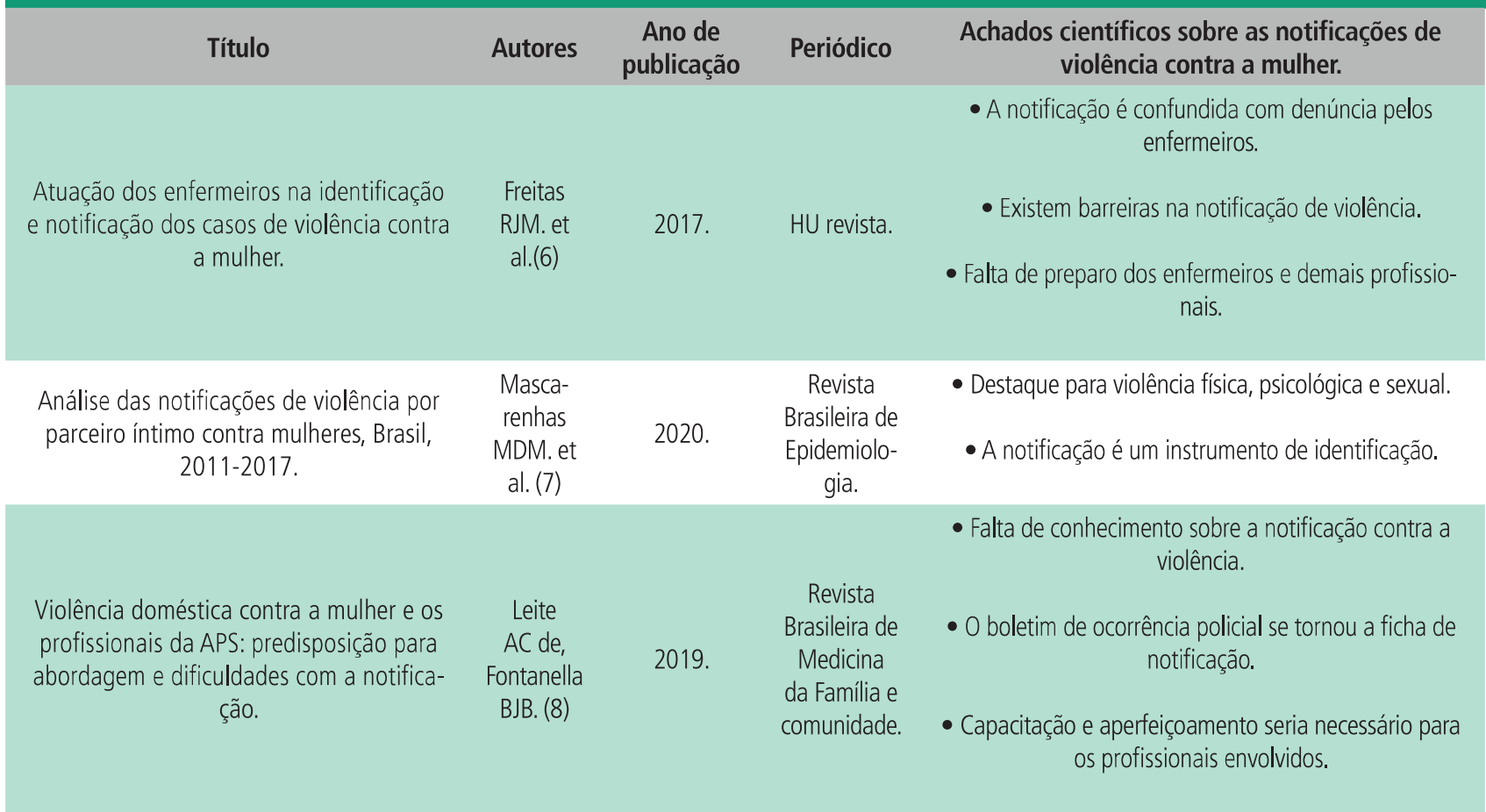

\begin{tabular}{|c|c|c|}
\hline $\begin{array}{l}\text { Subnotificação e invisibilidade da violência } \\
\text { contra a mulher. }\end{array}$ & $\begin{array}{c}\text { Alcantara } \\
\text { MCM. et } \\
\text { al. (9) }\end{array}$ & 2016. \\
\hline
\end{tabular}

\begin{tabular}{|c|c|c|c|c|}
\hline $\begin{array}{l}\text { Evolução da notificação de violência contra } \\
\text { mulher no município de São Paulo, 2008- } \\
2015 .\end{array}$ & $\begin{array}{l}\text { Neto } \\
\text { KREM, } \\
\text { Girianelli } \\
\text { VR. (10) }\end{array}$ & 2020. & $\begin{array}{l}\text { Ciência } \\
\text { e Saúde } \\
\text { Coletiva. }\end{array}$ & $\begin{array}{l}\text { - Violência física tem destaque no estudo. } \\
\text { - Existe a presença de casos de violência que não foram } \\
\text { notificados, por falta de conhecimento, abordagem e } \\
\text { conduta. }\end{array}$ \\
\hline $\begin{array}{l}\text { Indicadores da violência contra a mulher } \\
\text { provenientes das notificações dos serviços } \\
\text { de saúde de minas gerais-Brasil. }\end{array}$ & $\begin{array}{l}\text { Andrade } \\
\text { JO de. et } \\
\text { al. (11) }\end{array}$ & 2016. & $\begin{array}{c}\text { Texto } \\
\text { contexto } \\
\text { Enfermagem. }\end{array}$ & - Preenchimento inadequado da ficha de notificação. \\
\hline $\begin{array}{l}\text { (In)visibilidade da violência contra as mulhe- } \\
\text { res na saúde mental. }\end{array}$ & $\begin{array}{l}\text { Pedrosa } \\
\text { M, Zanello } \\
\text { V. (12) }\end{array}$ & 2016. & $\begin{array}{l}\text { Psicologia: } \\
\text { Teoria e } \\
\text { Pesquisa. }\end{array}$ & $\begin{array}{l}\text { - Profissionais com dificuldade para lidar com o tema/ } \\
\text { situação. } \\
\text { • Assistência sem direcionamento. }\end{array}$ \\
\hline
\end{tabular}

Fonte: dados da pesquisa, 2021.

É visível que a violência contra muIher persiste, e os atos agressivos têm aumentado, sendo que os motivos utilizados pelo homem como razão para justificar a continuidade dos atos de agressões à mulher são os mesmos, quais sejam: que ela não está fazendo o seu papel de cuidar dos filhos, de ser dona de casa, uma esposa carinhosa, em virtude de a mesma estar sim, dedicada a outras coisas, como ao trabalho
- Baixa capacitação relacionada a baixa notificação.

- 0 desafio é reconhecer a violência

- Violência física tem destaque no estudo.

Existe a presença de casos de violência que não foram conduta.

fora de casa, aos estudos, dentre outros. Ou seja, a perspectiva patriarcal continua sendo ressiginificada na sociedade atual ${ }^{(13,14,15,16,17,18)}$.

Quando se passa a utilizar o conceito de gênero fica mais notável perce- 
ber as desigualdades e discriminações decorrentes ao gênero, anteriormente vistos como normais pela maioria das sociedades, que podiam determinar qual comportamento era adequado à mulher, geralmente tendo como o esperado a mulher que seja sensível, protetora da família e do lar, responsável pela procriação, frágil, etc. Aos homens está reservado a solução dos problemas, o sustento da família, aquele que não pode expor seus sentimentos, porque é sinal de fraqueza ${ }^{(13,14,15,16,17,18)}$.

As características específicas que são atribuídas ao homem e a mulher, que os diferenciam, são decorrentes de cada cultura, que a sociedade impõe aos mesmos, acabando por naturalizar estes papéis sociais, que variam de sociedade para socieda$\operatorname{de}((13,14,15,16,17,18)$.

A violência contra mulher sempre existiu, na forma de agressão verbal, moral ou física resultando ou não em sua morte por suicídio ou homicídio. A maioria desses atos violentos infelizmente ocorre no ambiente doméstico onde a vítima geralmente conhece o agressor $(13,14,15,16,17,18)$. Os enfermeiros são vistos como elementos de grande importância para prestar essa assistência a estas mulheres vítimas de violência, visto que são formados para compreender a natureza complexa do conceito de saúde e bem-estar, como também o impacto dos fatores psicossociais e socioeconômicos como pobreza, etnia e gênero $(13,14,15,16,17,18)$.

Acredita-se que as mulheres buscam os serviços de saúde, após terem lesões físicas decorrentes das agressões. Logo, o cuidado clínico é uma forma de identificar e reconhecer a violência, apesar de não ser a única forma de atendimento, atuando como um momento de extrema importância para que essas mulheres sejam inseridas na rede de atendimento. Portanto, tanto os cuidados clínicos como os não clínicos são fundamentais e necessários na ação dos profissionais de en- fermagem ao cuidar dessas mulheres, tendo em vista que um completa o outro $(13,14,15,16,17,18)$.

Compreende-se por cuidados clínicos, o contato inicial do enfermeiro com a usuária e identificação de sinais e sintomas, bem como a aferição dos sinais vitais, exame das lesões em de-

\section{A violência contra mulher sempre existiu, na forma de agressão verbal, moral ou física resultando ou não em sua morte por suicídio ou homicídio}

corrência da agressão, além de encaminhamento para exames clínicos. Em um segundo momento, desenvolvem os cuidados não clínicos que compreendem a conversa, escuta e orientação a essas mulheres e famílias, mas nem todos os profissionais adotam essas medidas $(13,14,15,16,17,18)$.

É importante realizar uma boa anamnese com uma coleta de dados capaz de detalhar no prontuário da usuária as cenas de violência, garantindo e explicando a mesma sobre a sua autonomia em relação ao seu corpo para que a mulher possa identificar situações em que os seus direitos são violados. Para essa assistência completa a essas pacientes, é necessário que o enfermeiro conheça o seu território, bem como os demais serviços disponibilizados na rede para devidos encaminhamentos, tais como: Núcleo de Apoio à Saúde da Família (NASF), Ambulatórios Especializados, Policlínicas, Núcleos de Prevenção das Violências e Promoção da Saúde, Centros de Atenção Psicossocial (CAPS), Hospitais, Centros de Referência de Assistência Social (CRAS), Centros de Referência Especializados em Assistência Social (CREAS), Centro de Referência de Atenção à Saúde da Mulher em Situação de Violência (CRAM), Casa da Mulher Brasileira, entre outros(1).

Um marco importante para a Saúde da Mulher foi a implementação da Política Nacional de Atenção Integral à Saúde da Mulher no ano de 2004, que veio reforçar os aspectos já trazidos no Programa de Assistência Integral à Saúde da Mulher de 1984, além de incluir grupos até então excluídos dos serviços de saúde, como: indígenas, lésbicas, mulheres privadas de liberdade, deficientes, dentre outros, como também alguns serviços até então não contemplados, dentre eles, climatério, intensificação da prevenção de infecções sexualmente transmissíveis (IST's), reduzir a morbimortalidade por câncer na população feminina, como também prestar assistência à mulheres vítimas de violência sexual, doméstica e ou intrafamiliar(4). Os profissionais de enfermagem precisam estar mais preparados para acolher as mulheres vítimas de violência, e não somente isto, mas rastrear também, pois existe uma fragilidade quanto a isso(18). 


\section{CONCLUSÃO}

A pesquisa analisou as notificações no estado da Paraíba, e percebeu-se que houve altos índices, e que merecem atenção dos profissionais de todas as áreas. A violência contra a mulher é um problema de saúde pública, social e educacional, e por vezes, é negligenciada pela sociedade, por medo e opressão. A mulher precisa de rede de apoio e segurança ofertada pelos serviços federais, estaduais e municipais, para que possa ter o cuidado que necessita próximo a ela.

Recomenda-se novos estudos sobre o tema, e com a enfermagem não é diferente, visto que o enfermeiro é um profissional que está presente constantemente na vida da mulher, em vários ciclos, na concepção, gestação, puerpério, reprodução, prevenção de doenças crônicas, e outros cuidados direcionados a mulher. É importante que os profissionais busquem maior conhecimento sobre o assunto, e qualifiquem-se para melhor assistir suas pacientes.

\section{Referências}

1. Brasil. Ministério da Saúde, Instituto Sírio-Libanês de Ensino e Pesquisa. Protocolos da atenção básica: saúde das mulheres. Brasília: Ministério da Saúde, 2016.

2. Silva EB da. et al. Violência contra a mulher: limites e potencialidades da prática assistencial. Acta paul. enferm. São Paulo,v. 26, n. 6, p. 608613, 2013.

3. Brasil. Violência contra a mulher. 2018.

4. Brasil. Política Nacional de enfrentamento da violência contra a mulher. 2010

5. Centro Estadual de Vigilância em saúde. 2011.

6. Freitas RJM. et al. Atuação dos enfermeiros na identificação e notificação dos casos de violência contra a mulher. HU Revista. v. 43, n.2, 2017.

7. Mascarenhas MDM. et al. Análise das notificações de violência por parceiro íntimo contra mulheres, Brasil, 2011-2017. Revista Brasileira de Epidemiologia. 2020.

8. Leite AC de, Fontanella BJB. Revista Brasileira de Medicina da Família e comunidade. 2019

9. Alcantara MCM. et al. Subnotificação e invisibilidade da violência contra a mulher. Repositório Institucional da Universidade Federal de Outro Preto. 2016.

10. Neto KREM, Girianelli VR. Evolução da notificação de violência contra mulher no município de São Paulo, 2008-2015. Ciência e Saúde coletiva.
2020.

11. Andrade J0 de. et al. Indicadores da violência contra a mulher provenientes das notificações dos serviços de saúde de minas gerais-Brasil. Texto Contexto Enfermagem. 2016.

12. Pedrosa $M$, Zanello V. (In)visibilidade da violência contra as mulheres na saúde mental. Psicologia: Teoria e Pesquisa. 2016.

13. Sousa LP de, Guedes DR. A desigual divisão sexual do trabalho: um olhar sobre a última década. Estud. av. 30 (87), 2016.

14. Beal ML de. et al. Uma reflexão acerca do feminicídio. $3^{\circ}$ Simpósio de Sustentabilidade e Contemporaneidade nas Ciências Sociais, 2015.

15. Netto LA de. Atuação da enfermagem na conservação da saúde de mulheres em situação de violência. Revista Mineira de Enfermagem. 2018.

16. Santos J, Dantas MSSS, Reis LA, Duarte SFP. Atuação da equipe de Enfermagem em unidades de saúde da família no atendimento à mulher vítima de violência. Rev Enferm Contemporânea. 2014,15;3(1):15-26.

17. Brasil. Ministério da Saúde. Política Nacional de Atenção Integral à Saúde da Mulher: Princípios e Diretrizes. Brasília, 2004.

18. Silva AV. et al. Conhecimento de acadêmicos de enfermagem acerca da violência contra mulher. Nursing (Säo Paulo); 22(251): 2926-2931, abr.2019. 